بررسى تحليلى و استنادى توليدات علمى اعضاى هيأت علمى طب سنتى دانشخاههاى علوم

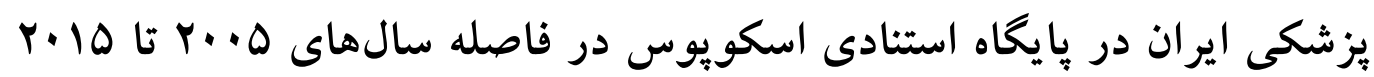

$$
\begin{aligned}
& \text { مريم كازرانى ا**، مرضيه باقرى قهفرخى '، مريم شكفته' } \\
& \text { ا- استاديار، دانشكاه علوم يزشكى شهيد بهشتى، دانشكده بيرايزشكى، گروه كتابدارى و اطلاعرسانى يزشكى، }
\end{aligned}
$$

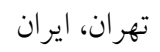

$$
\begin{aligned}
& \text { ז- كارشناس ارشد كتابدارى و اطلاعرسانى بزشكى، دانشكاه علوم بز شكى شهيد بهشتى، دانشكده بيرايزشكى، }
\end{aligned}
$$

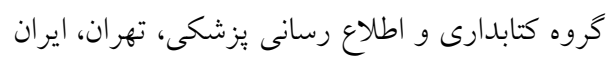

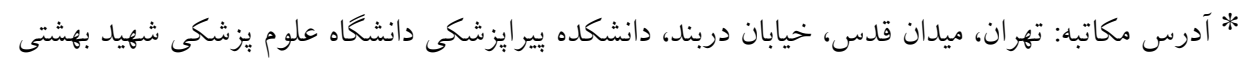

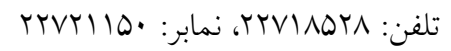

$$
\begin{aligned}
& \text { يُ }
\end{aligned}
$$

doi: $10.29252 / j m p .2 .70 .45$ 9V/r/A تاريخ تصويب

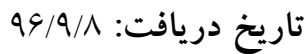

جكيده

مقدمه: يكى از مهمترين جنبههاى بزوهش، بررسى و ارزيابى توليدات علمى است و اين امر در طب سنتى به دليل كاربرد خاصى كه

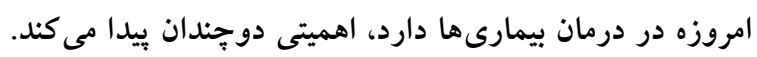

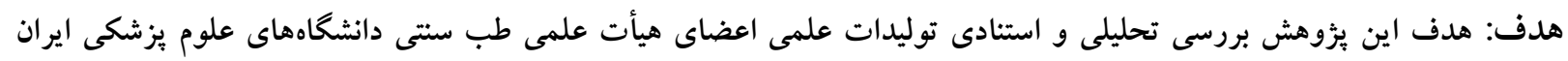

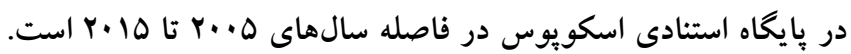

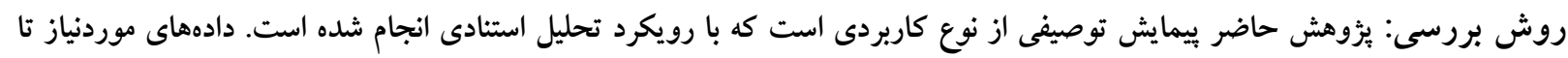

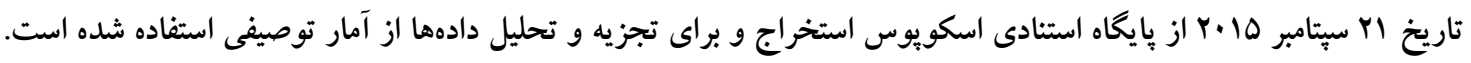

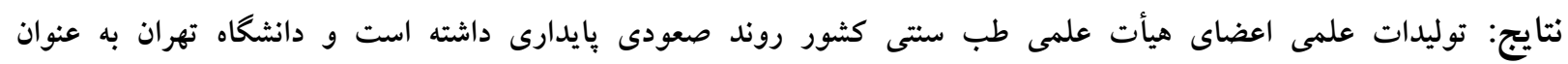

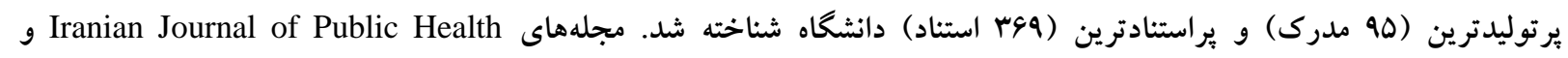
Iranian Red Crescent Medical Journal

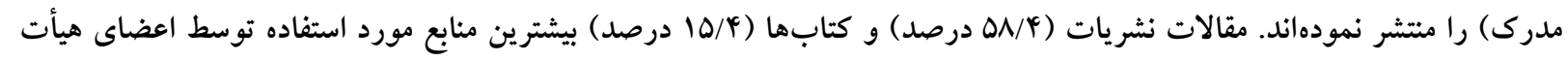

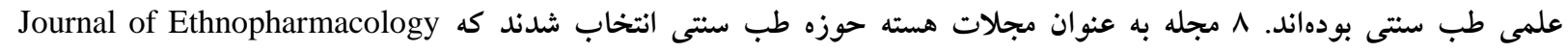

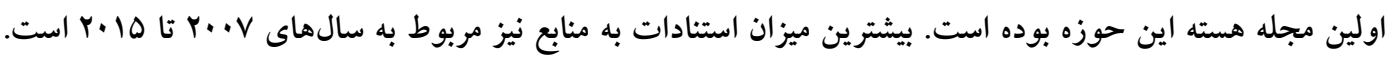

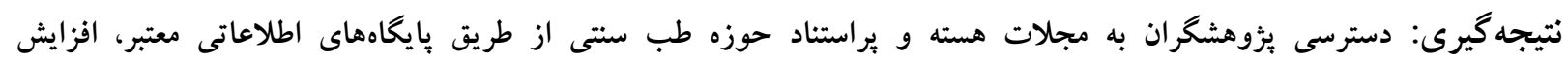

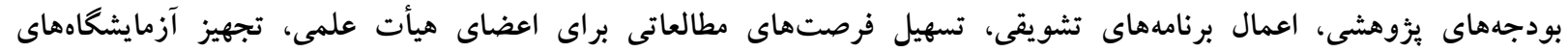

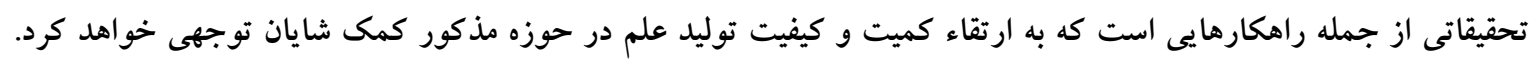
كَل وازگًان: اسكويوس، اعضاى هيات علمى، ايران، تحليل استنادى، طب سنتى، دانشخاههاى علوم يزشكى 
و فنى، معرفى بيشگامان عرصه تحقيق، تعيين تأثير منابع و مقدمه شناخت ساختار فكرى در يك رشته خاص با روش مذ مذكور

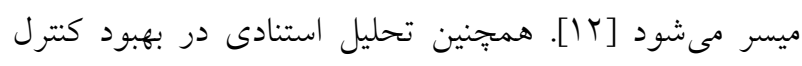

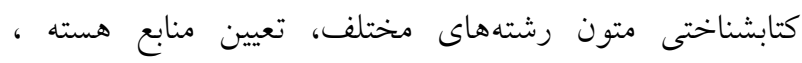

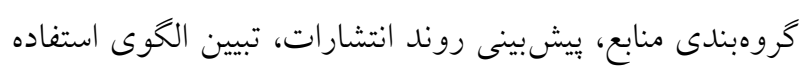

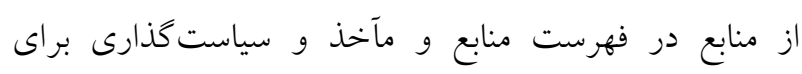

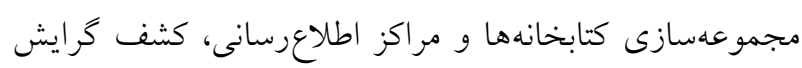
نويسندكان در استفاده از منابع متفاوت اطلاعاتى (كتاب، مراب، مقاله، جاياننامه و غيره)، تعيين روزآمدى منابع مورد استفاده در آثار

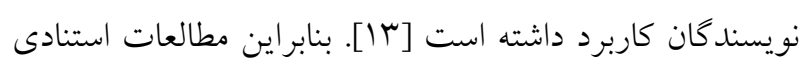
به عنوان يكى از مهمترين جنبههاى ارزيابى فعاليتهاى

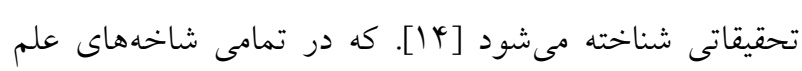
بويزه در حوزه سلامت در حال كسترش است. طبسنتى كه

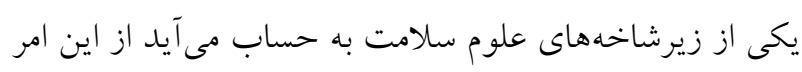

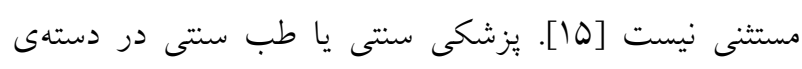
بز شكى جايكزين قرار مى كيرد.

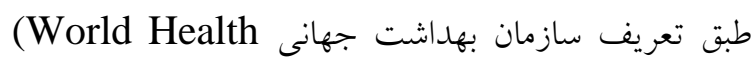
Organization)

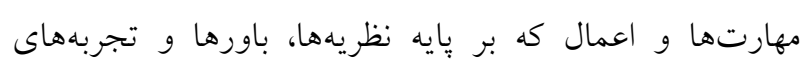

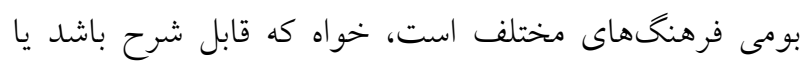

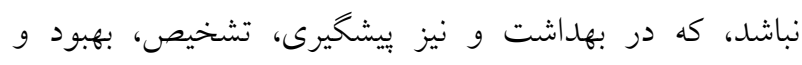

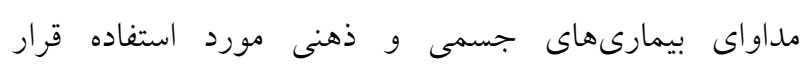

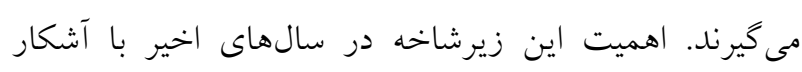

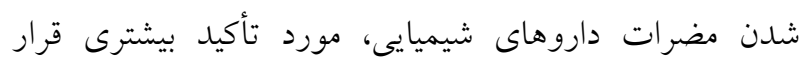

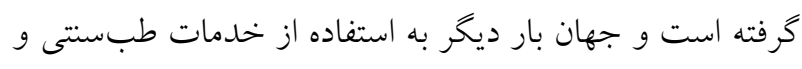

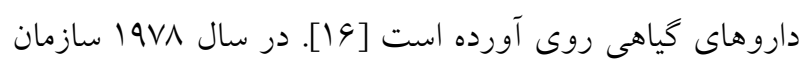

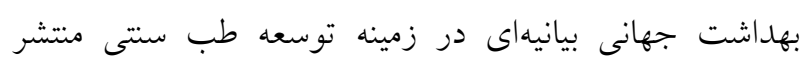

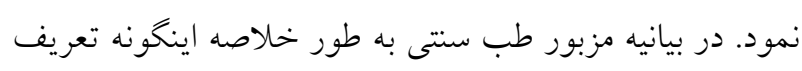

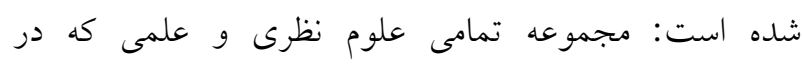

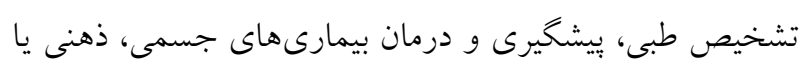

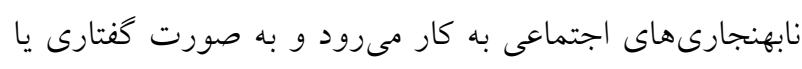

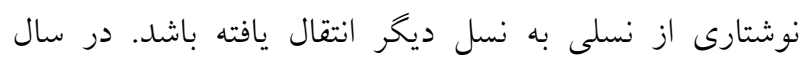

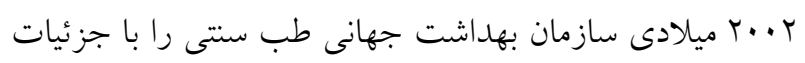

سنجش و ارزيابى علم، حوزهاى يويا و در حال رشد است.

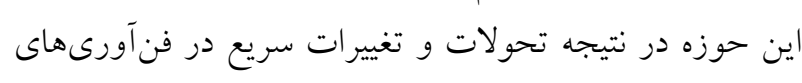

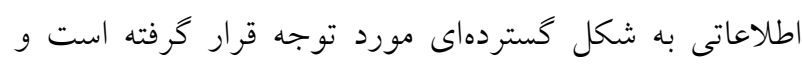

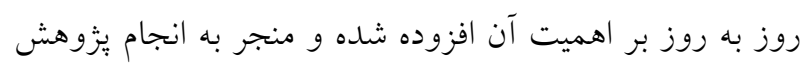

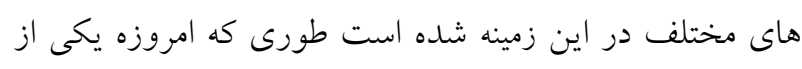

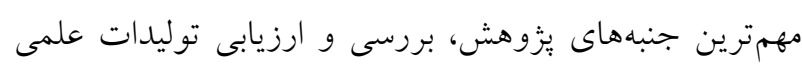

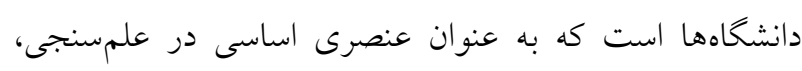

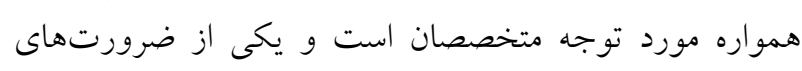
جوامع علمى و دانشخاهى كشور تلقى مىشود.

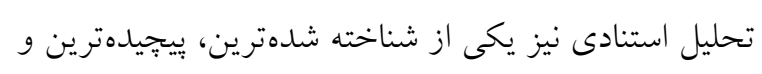

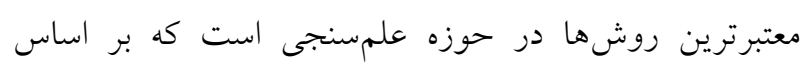
تحليل استنادهاى يك مدرى از منظرهاى كوناكون انجام

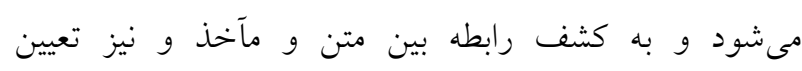
ويزگى هاى يك زمينه موضوعى از طريق بررسى دقيق متون آن

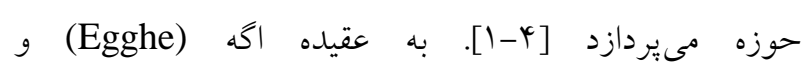

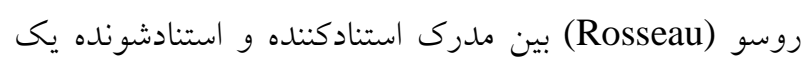
نوع رابطه از نظر موضوع، روشن مشناسى و غيره وجود دارد،

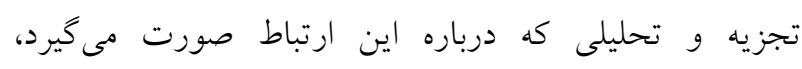

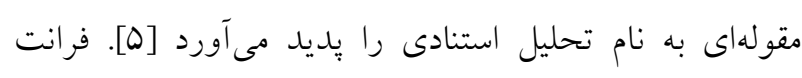
عقيده دارد كه تحليل استنادى از طريق (اعمال (Ferrante)

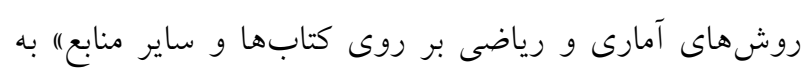

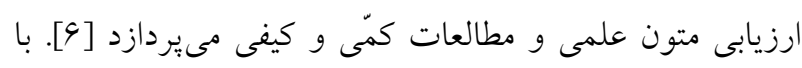

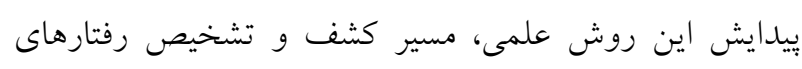

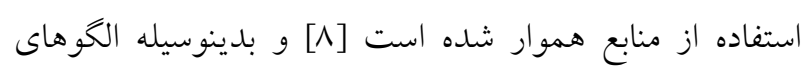
ارتباط علمى در حوزههاى مختلف دانش نمايان مىشود [9. به كونهاى كه كلارى (Clarke) تحليل استنادى را ابزار

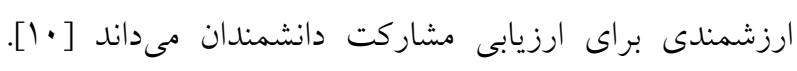

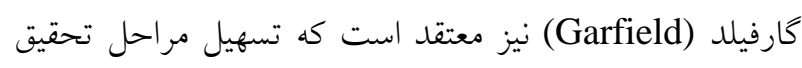

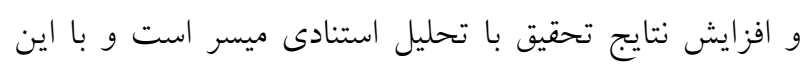

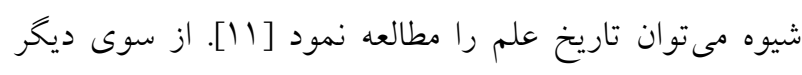

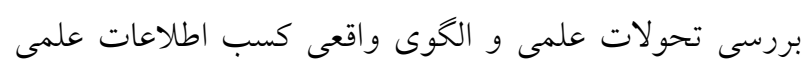


عبارت است از كليه توليدات علمى اعضاى هيأت علمى گروه-

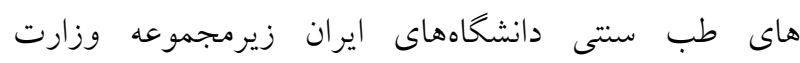

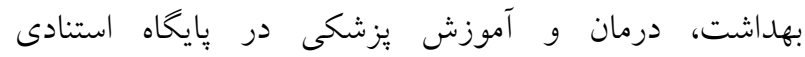

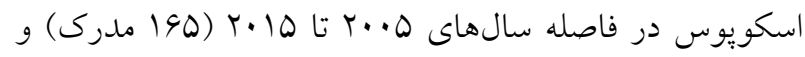

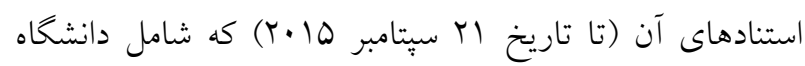

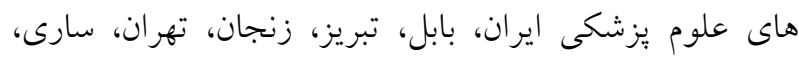

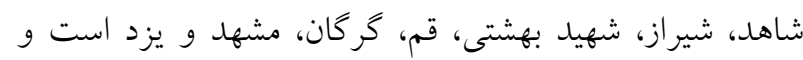

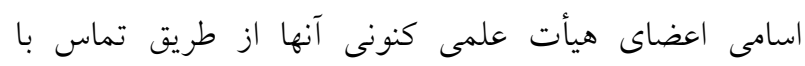

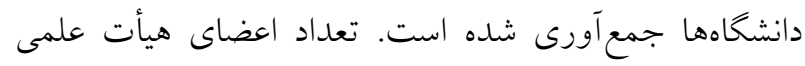

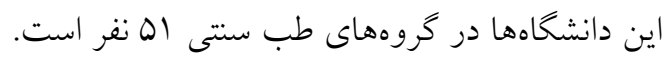

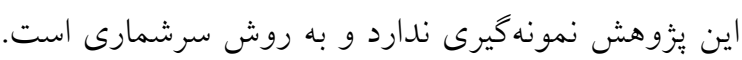

\section{براى تعيين جامعه يزوهش:}

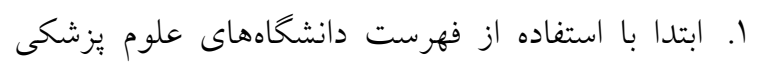

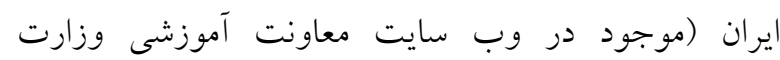

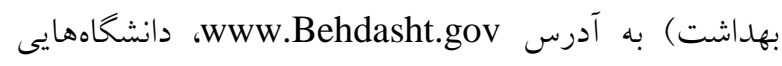
كه داراى دانشكده و مراكز تحقيقات طب سنتى هستند،

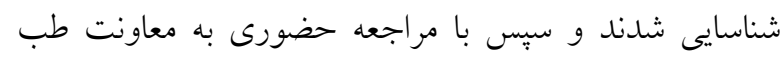

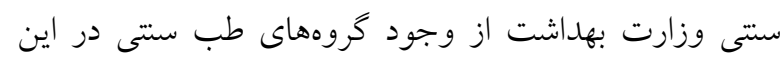

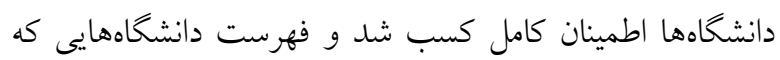
براى تشكيل گروه طب سنتى مجوز گرفته بودند، تهيه شد.

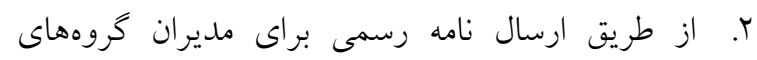

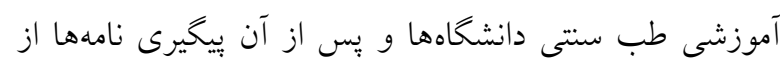

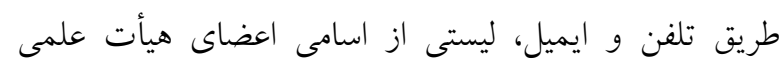

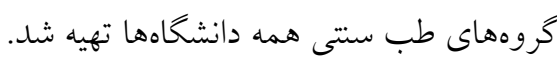

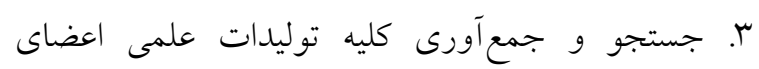
هيأت علمى طب سنتى كشور در يايخاه استنادى اسكويوس إنس

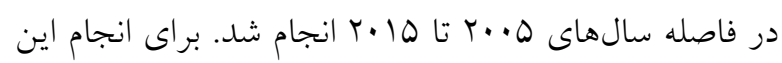

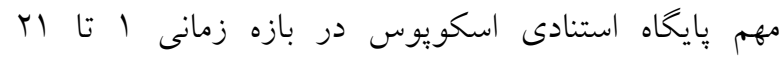

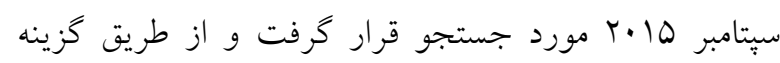

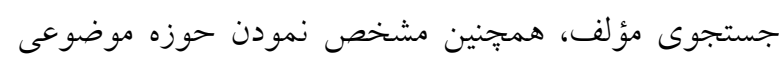

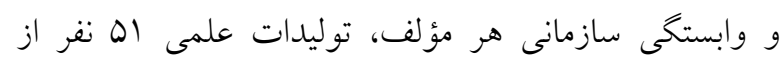

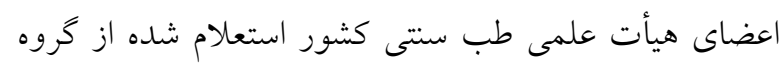

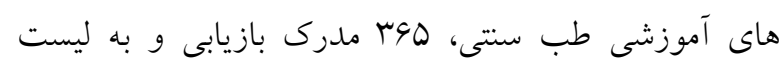
منتقل و ذخيره شد، البته به دليل اين كه فرمت مستندى ازئ ماز نام
بيشترى اينخونه تعريف نموده است: طب سنتى وازهاى كلى

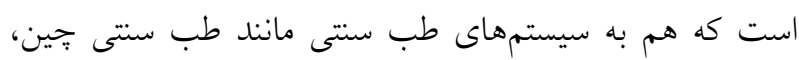

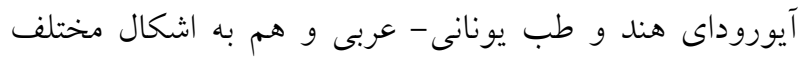

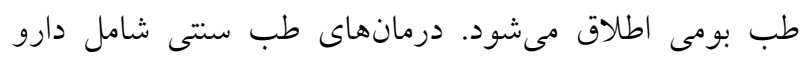

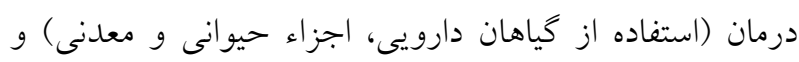

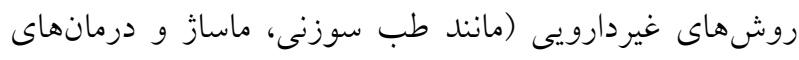
روحى و روانى) مىباشد. در كشورهايى كه سيستم خدمات

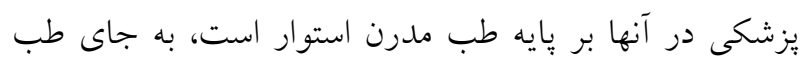

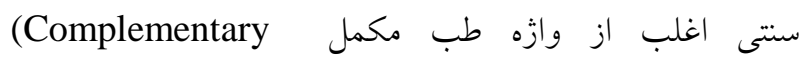

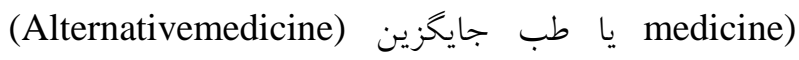
استفاده مىشود. در حال حاضر از نحاه سازمان جهانى بهداشت

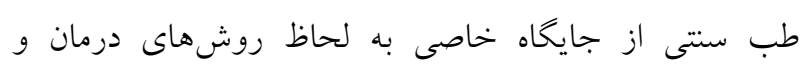

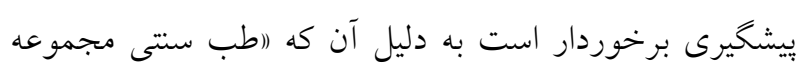

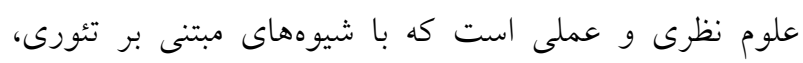

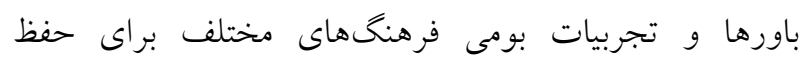

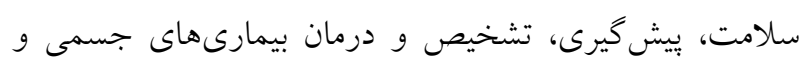

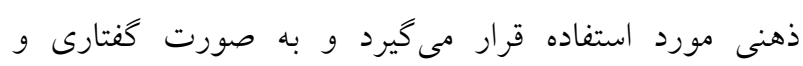

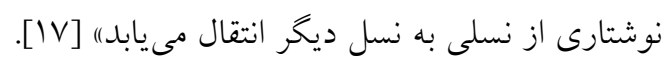

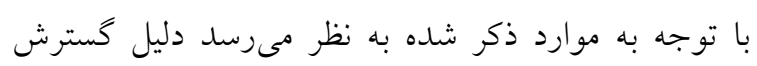

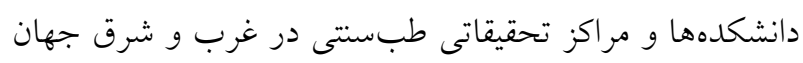

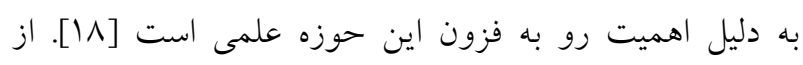

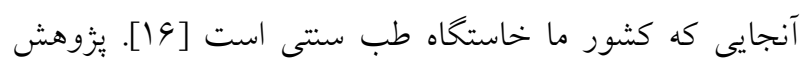

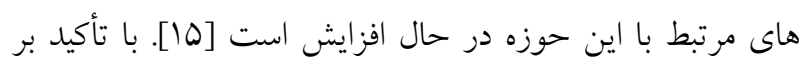

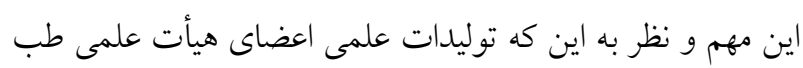

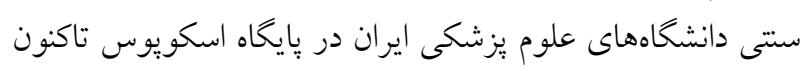

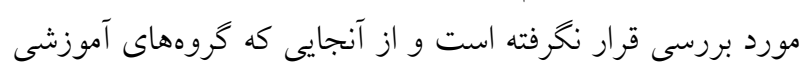

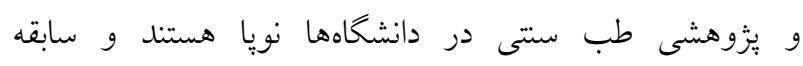

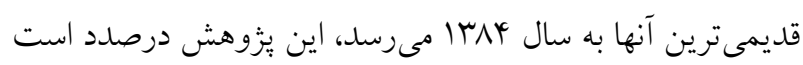

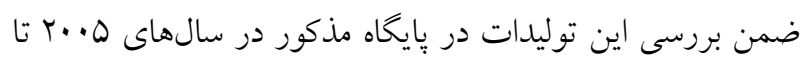
10 آب، به تحليل استنادى آنها بيردازد.

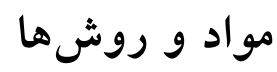

اين يزوهش از نوع كاربردى است و با روش بيمايشى

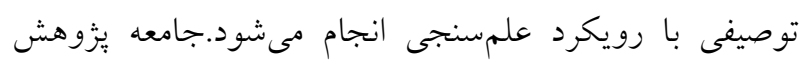


محاسبات مربوطه صورت مىيذيرد، براى تعيين مجلات هسته و محاسبه ضريب برادفورد از روش زير استفاده شد:

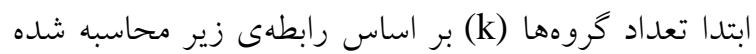

بيشترين استناد صورت گُفته به يك نشريه / تعداد كل k= استنادات به نشريات لاتين

بدينترتيب با توجه به اين كه تعداد كل استنادها به

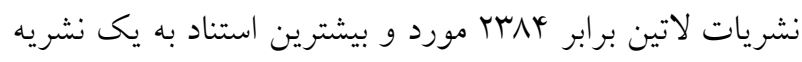
المورد بوده است لذا تعداد كروهها برابر با 19 محاسبه شد. با توجه به تعداد گروهها، مجالات به ترتيب بيشترين استنادها، از زياد به كم مرتب شد و در 19 طبقه به صورت زير هم قرار

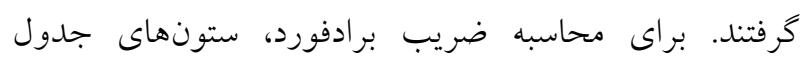
تعريف و محاسبات لازم در جدول انجام گرفت. با توجه به مقادير برادفورد به دست آمده براى هر طبقه،

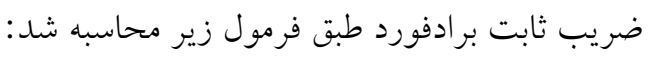

$$
\begin{aligned}
& b=\frac{\sum_{i=1}^{k} b m_{i}}{k}=\frac{20.58}{16}=1.29 \\
& R(n)=a \cdot n^{b}: \text { با جايخذارى ثابت برادفورد در رابطه }
\end{aligned}
$$

تعداد مجلات هسته (n) محاسبه شد. در رابطه بالا (Rn) تعداد كل استنادها، (a) تعداد استناد به مجله با بيشترين استناد، ضريب ثابت برادفورد و (n) تعداد مجلات هسته مى باشد. (b) بعد از جايخذارى مقادير به دست آمده در رابطه بالا و حل $\mathrm{n}=8$

$$
\text { معادلات لازم، تعداد مجلات هسته برابر: }
$$

به دست آمد، كه با توجه به بيشترين استنادات صورت كرفته به نشريات، مجلات هسته شامل ^ مجله است.

\section{نتايج}

كل مقالات اعضاى هيأت علمى كنونى طب سنتى كشور

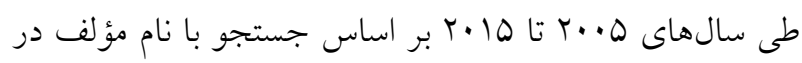

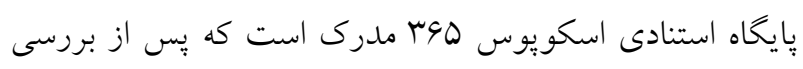

افراد به زبان انخليسى موجود نبود، تمام فرمتهاى ممكن اسامى اعضاى هيأت علمى مورد جستجو قرار گرفت و نتايج

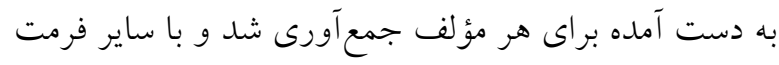

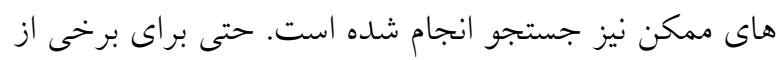
اعضاى هيأت علمى كه قبلاً عضو هيأت علمى دانشخاه ديخرى بودند و اكنون به دانشخاه ديخرى منتقل شده بودند با هات هر دو وابستكى سازمانى جستجو انجام شد تا همه توليدات علمى در يزٔوهش وارد شوند. درنهايت براى اله عضو هيأت

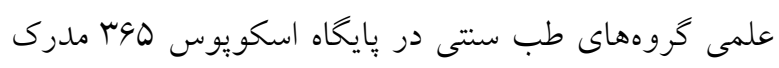
بازيابى و ذخيره شد.

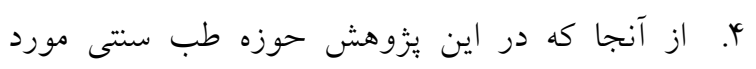
بررسى بوده است و تعداد بسيارى از توليدات علمى اعضاى

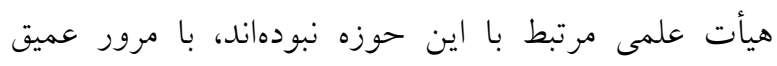

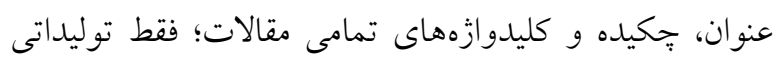
كه در حوزه طب سنتى بودند انتخاب، و بقيه ركوردها از

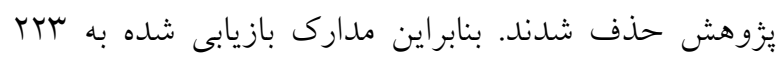
مدرى اعضاى هيأت علمى طب سنتى دانشخاههاى علوم يزشكى كشور در حوزه طب سنتى محدود شد.

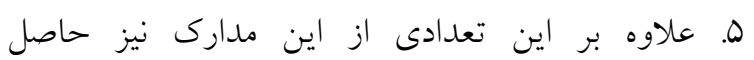
همكارى بين اعضاى هيأت علمى بوده و زير نام هركدام به

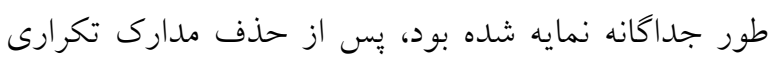

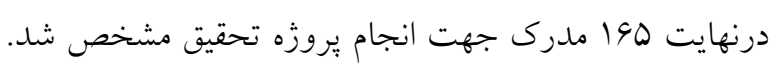
درنهايت با استفاده از روشهاى آمارتوصيفى و امكانات نرم

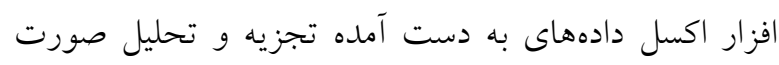

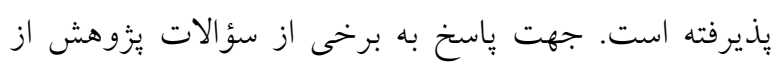

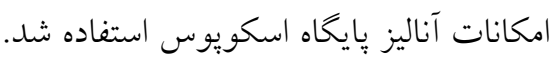
9. براى دستهبندى موضوعى توليدات علمى يزّوهشخران،

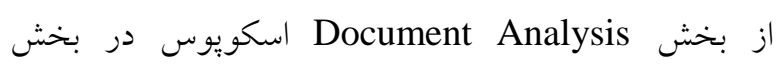
Subject area ميانخين درصد موضوعى محاسبه شد.

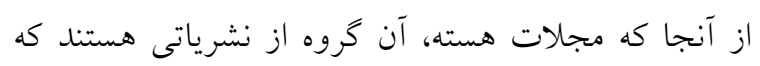

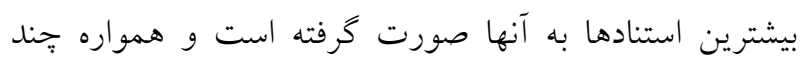
جايخاه نخست صدر فهرست رتبهبندى را به خود اختصاص بـ به

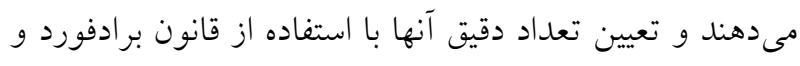




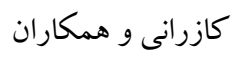

(Health professions)

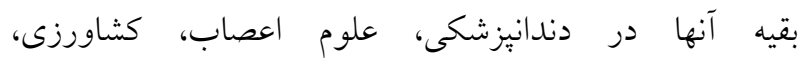
ايمنىشناسى و ميكروبيولوزى، شيمى و علوم ميان رشتهاى (Multidisiplinary)

همانطور كه در جدول شماره ا مشاهده مىشود، دانشگاه

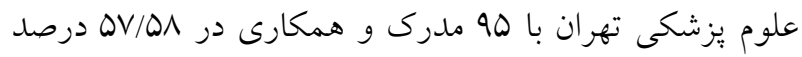

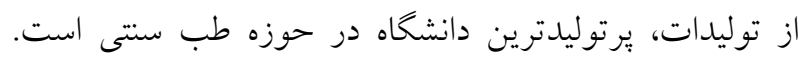

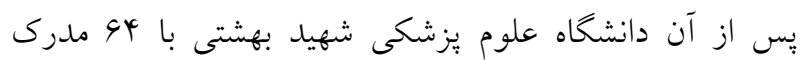

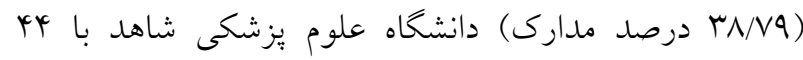
مدرى (qV/Grادرصد مدارى) رتبههاى بعدى را از نظر تعداد توليدات علمى به خود اختصاص دادهاند.
موضوعى، س T مدرك آن در حوزه طب سنتى بوده است. به

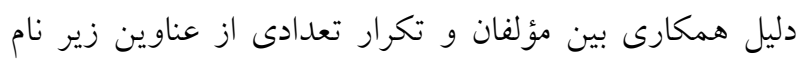
مؤلفان مختلف، مدارى تكرارى حذف شده و تعداد 190

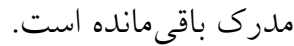
همان طور كه در نمودار شماره ا ملاحظه مىشود توليدات

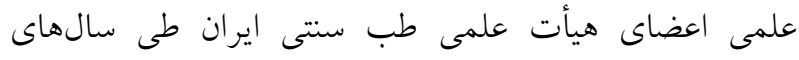

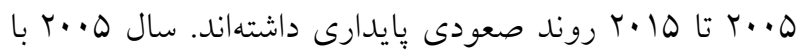

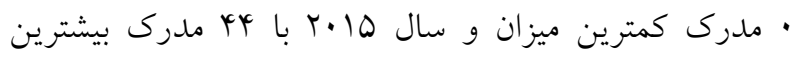
ميزان توليد علمى را دارا هستند.

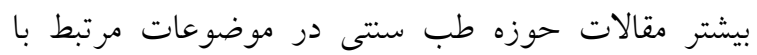

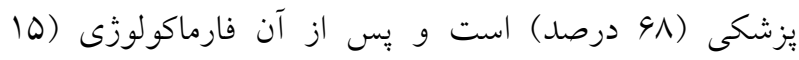

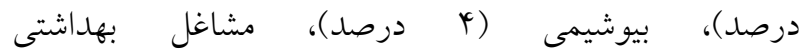

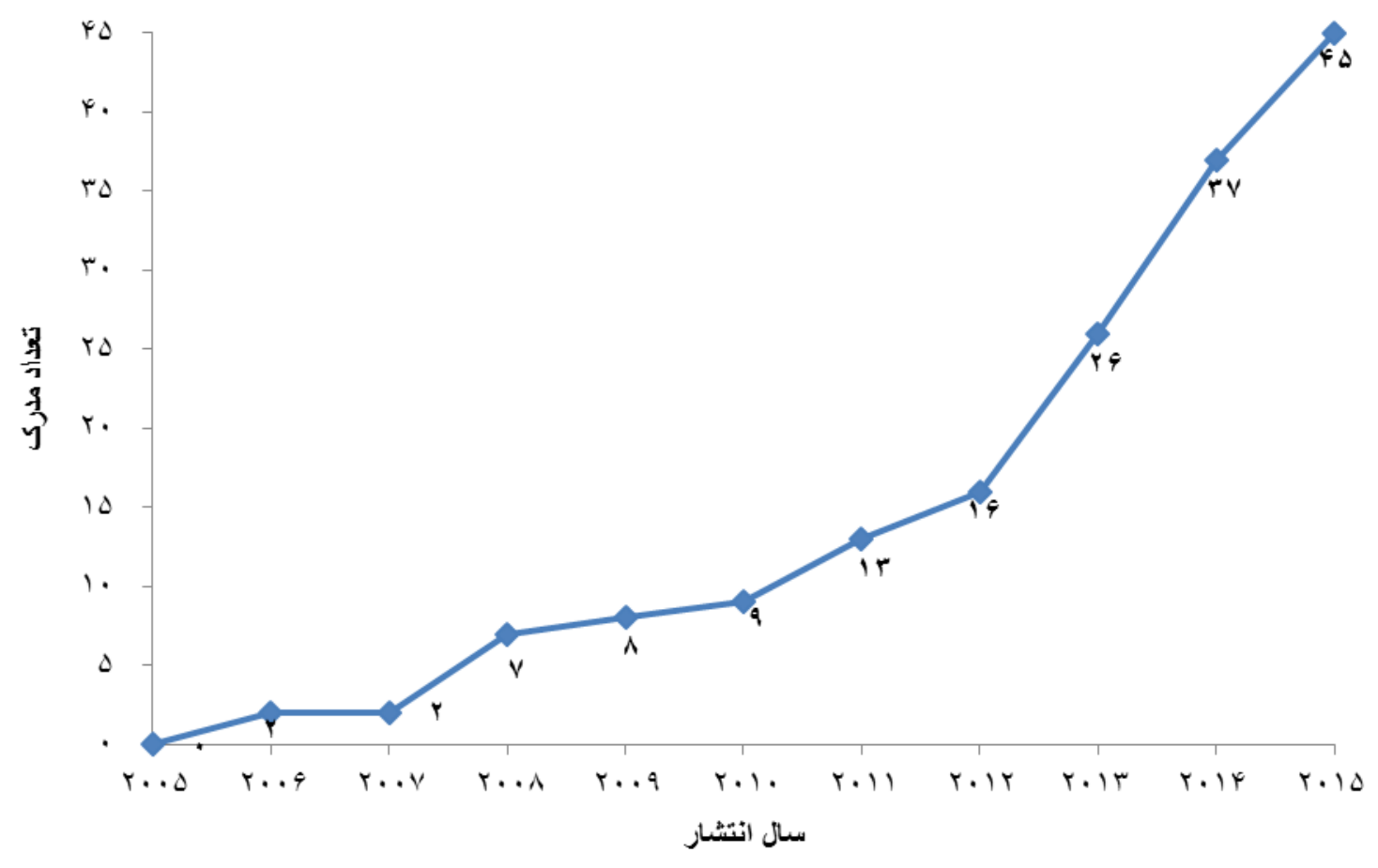

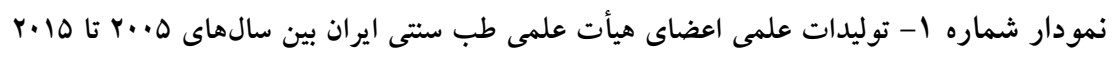




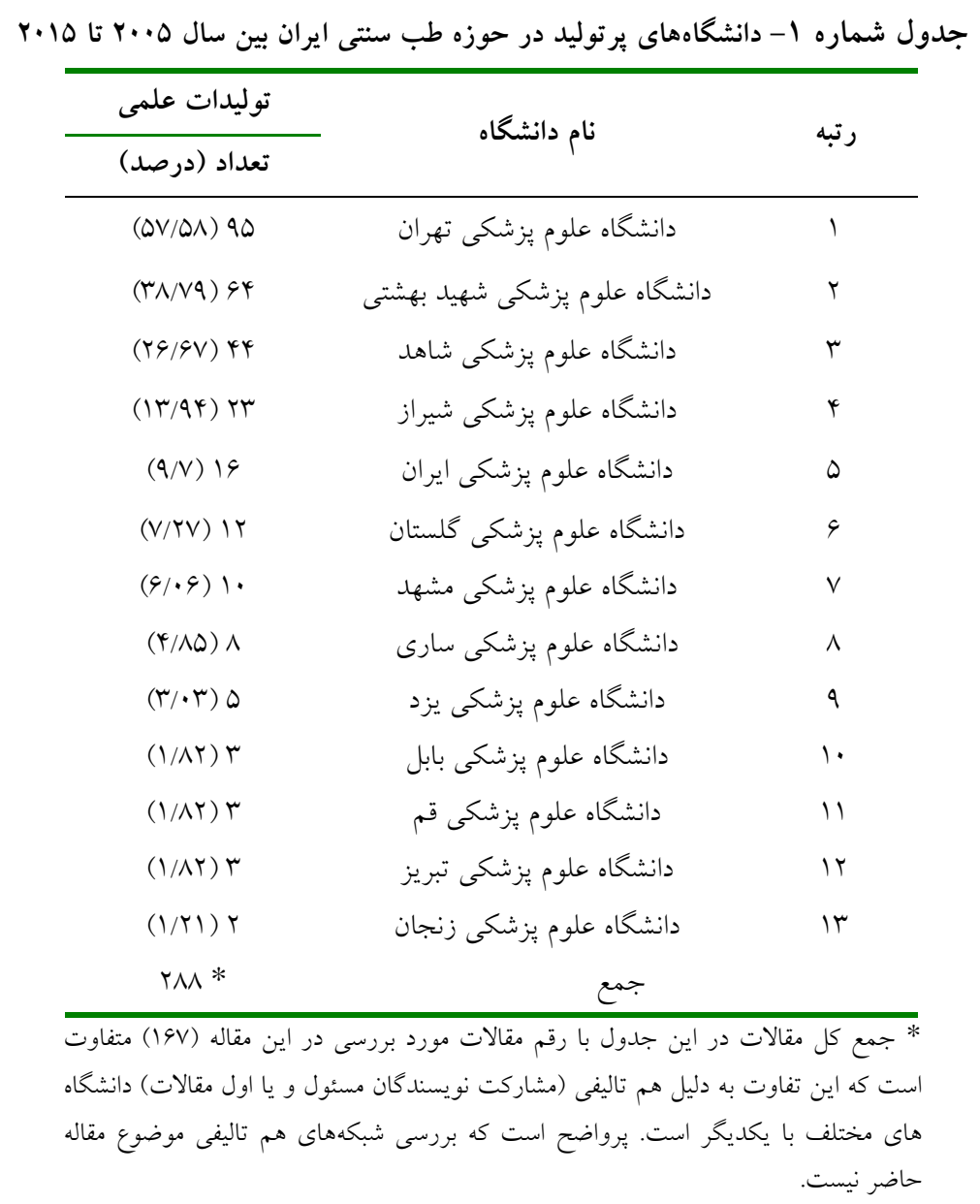

همانطور كه در جدول شماره r مشاهده مىشود مجلههاى

Iranian Red و Iranian Journal of Public Health Crescent Medical Journal

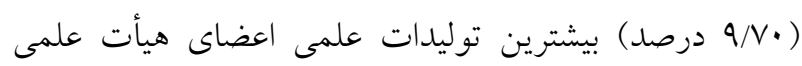

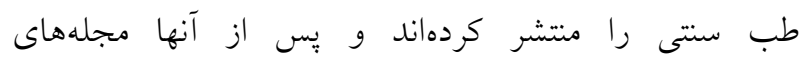
$\Delta / 4 \Delta$ (International Journal of Cardiology Journal of Evidence-Based و درصد) $\wedge$ Cبmplementary and Alternative Medicine مدرى (Y/ND درصد) رتبه مهاى بعدى را به خود اختصاص داده
همانطور كه در جدول شماره r مشاهده مىشود به 190

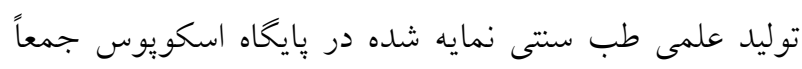

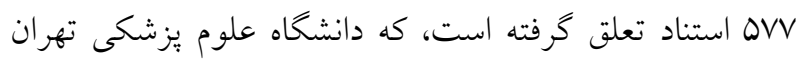

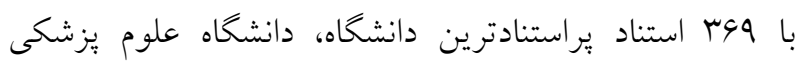

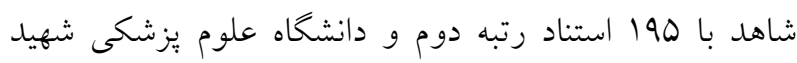

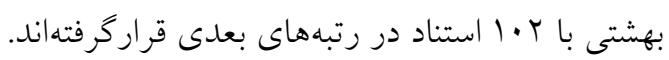

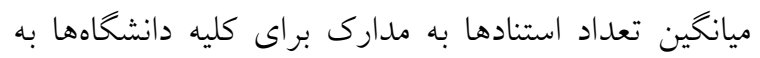

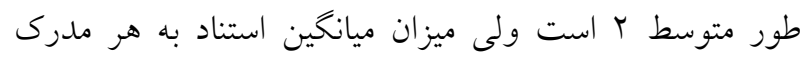

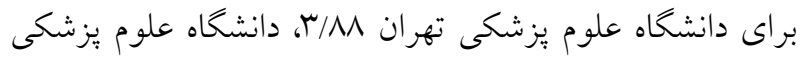

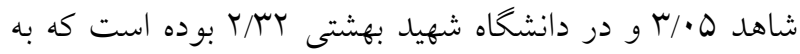

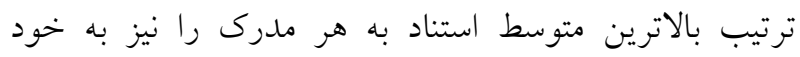
اختصاص دادهانل. 


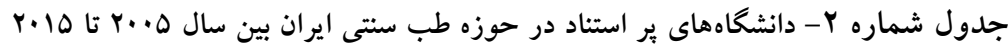

\begin{tabular}{|c|c|c|c|}
\hline ميانگين تعداد استناد به هر مدرى & تعداد (درصد) & نام دانشگاه & رتبه \\
\hline$r / \Lambda$ & $(9 \% / 90)+49$ & دانشكاه علوم يزشكى تهران & 1 \\
\hline$\mu / \cdot \Delta$ & ( & دانشخاه علوم يزشكى شاهد & r \\
\hline t/MT & $(\mid V / 9 \Lambda) \mid \cdot r$ & دانشخاه علوم يزشكى ث & r \\
\hline$r / T \varphi$ & $(9 / \cdot 1) \Delta r$ & دانشگاه علوم يزشكى حلستان & $r$ \\
\hline$r / T$ & $(\Delta / \wedge q) \mu Y$ & دانشكاه علوم يزش & $\Delta$ \\
\hline r & $(\Psi / 19) Y \Psi$ & دانشخاه علوم يزشكى يزد & 4 \\
\hline 1 & $\left(1 / N{ }^{\mu}\right) 1$ & دانشخاه علوم بزشكى سارى & 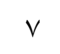 \\
\hline$\cdot / V Q$ & $(1 / \cdot 4)^{4}$ & دانشگاه علوم يزشكى تبريز & $\wedge$ \\
\hline $1 / 4$ & $(1 / \cdot 4)^{4}$ & دانشگاه علوم يزشكى قم & 9 \\
\hline $1 / 9 \mathrm{~V}$ & $(\cdot / \wedge V) \Delta$ & دانشخاه علوم يزشكى مشهد & 1. \\
\hline $1 / 9 \mathrm{~V}$ & $(\cdot / \wedge V) \Delta$ & دانشگاه علوم يزشكى بابل & 11 \\
\hline 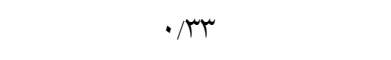 & $(\cdot / I V) I$ & دانشخاه علوم يزشكى ايران & ir \\
\hline 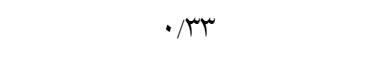 & $(\cdot / \mathrm{IV}) 1$ & دانشكاه علوم يزشكى زنجان & ir \\
\hline r & $(1 \cdots) \Delta V V$ & كليه دانشگاهها & \\
\hline
\end{tabular}

جدول شماره r- مجلات منتشر كنده توليدات علمى اعضاى هيأت علمى طب سنتى ايران بين سالهاى ه.بr تا 10.r

\begin{tabular}{|c|c|c|}
\hline رتبه & نام مجله & تعداد (درصد) \\
\hline 1 & $\begin{array}{l}\text { Iranian Journal of Public Health } \\
\text { Iranian Red Crescent Medical Journal }\end{array}$ & $(9 / \mathrm{V}) 19$ \\
\hline r & International Journal of Cardiology & $(0 / 40) q$ \\
\hline r & Journal of Evidence-Based Complementary and Alternative Medicine & $(\uparrow / \wedge \Delta) \wedge$ \\
\hline r & Journal of Medicinal Plants & $(Y / T Y) V$ \\
\hline 0 & $\begin{array}{l}\text { Iranian Journal of Reproductive Medicine } \\
\text { Physiology and Pharmacology }\end{array}$ & $\left(Y / K^{C}\right) \mathcal{F}$ \\
\hline 4 & $\begin{array}{l}\text { Complementary Therapies in Medicine } \\
\text { DARU, Journal of Pharmaceutical Sciences } \\
\text { International Journal of Preventive Medicine } \\
\text { Iranian Journal of Obstetrics, Gynecology and Infertility } \\
\text { Journal of Mazandaran University of Medical Sciences } \\
\text { Pakistan Journal of Biological Sciences }\end{array}$ & $(1 / A T) r$ \\
\hline
\end{tabular}


ادامه جدول شماره ب-

\begin{tabular}{|c|c|c|}
\hline رتبه & 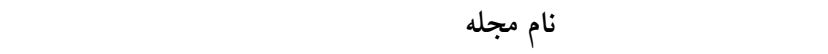 & تعداد (درصد) \\
\hline & Advances in Environmental Biology & \\
\hline \multirow[t]{32}{*}{ 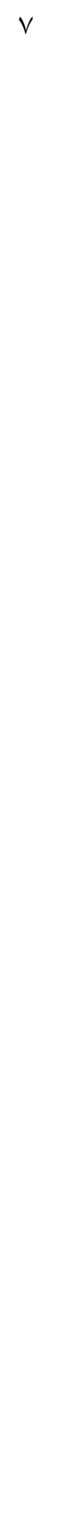 } & Archives of Iranian Medicine & $(1 / T) Y$ \\
\hline & Complementary Therapies in Clinical Practice & \\
\hline & Daru & \\
\hline & Daru : journal of Faculty of Pharmacy, Tehran University of Medical Sciences & \\
\hline & Integrative Cancer Therapies & \\
\hline & International Journal of Surgery & \\
\hline & Iranian Journal of Basic Medical Sciences & \\
\hline & Journal of Babol University of Medical Sciences & \\
\hline & Journal of Ethnopharmacology & \\
\hline & Journal of Medicinal Plant Research & \\
\hline & Pharmaceutical Biology & \\
\hline & Phytotherapy Research & \\
\hline & Saudi Medical Journal & \\
\hline & Acta Horticulturae & \\
\hline & Acta Medica Iranica & \\
\hline & Advanced Pharmaceutical Bulletin & \\
\hline & African Journal of Microbiology Research & \\
\hline & African Journal of Traditional, Complementary and Alternative Medicines & \\
\hline & Alimentary Pharmacology and Therapeutics & \\
\hline & American Journal of Gastroenterology & \\
\hline & AMHA - Acta Medico-Historica Adriatica & \\
\hline & Archives of Medical Science & \\
\hline & Asian Pacific Journal of Tropical Biomedicine & \\
\hline & BMC Complementary and Alternative Medicine & \\
\hline & Chinese Journal of Integrative Medicine & \\
\hline & Eastern Mediterranean Health Journal & \\
\hline & European Journal of Integrative Medicine & \\
\hline & Explore: The Journal of Science and Healing & \\
\hline & Focus on Alternative and Complementary Therapies & \\
\hline & Food and Agricultural Immunology & \\
\hline & Food and Chemical Toxicology & \\
\hline & Gazzetta Medica Italiana Archivio per le Scienze Mediche & \\
\hline \multirow[t]{10}{*}{$\wedge$} & Immunopharmacology and Immunotoxicology & $(\cdot / 91) 1$ \\
\hline & Infectious Diseases in Clinical Practice & \\
\hline & International Journal of Food Sciences and Nutrition & \\
\hline & International Journal of Morphology & \\
\hline & International Journal of Phytomedicine & \\
\hline & Iranian Journal of Cancer Prevention & \\
\hline & Iranian Journal of Pediatrics & \\
\hline & Iranian Journal of Pharmaceutical Research & \\
\hline & JAMS Journal of Acupuncture and Meridian Studies & \\
\hline & Journal of acupuncture and meridian studies & \\
\hline
\end{tabular}




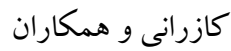

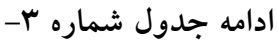

\begin{tabular}{|c|c|c|}
\hline رتبه & 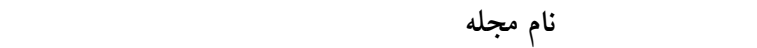 & تعداد (درصد) \\
\hline & Journal of Alternative and Complementary Medicine & \\
\hline & Journal of Complementary and Integrative Medicine & \\
\hline & Journal of Cosmetic and Laser Therapy & \\
\hline & Journal of Diabetes and Metabolic Disorders & \\
\hline & Journal of Dietary Supplements & \\
\hline & Journal of Drugs in Dermatology & \\
\hline & Journal of Essential Oil-Bearing Plants & \\
\hline & Journal of integrative medicine & \\
\hline & Journal of Medical Sciences & \\
\hline & Journal of Medicinal Plants Research & \\
\hline & Journal of Religion and Health & \\
\hline & Journal of Research in Medical Sciences & \\
\hline & Journal of Traditional and Complementary Medicine & \\
\hline & Journal of Zanjan University of Medical Sciences and Health Services & \\
\hline & Jundishapur Journal of Natural Pharmaceutical Products & \\
\hline & Life Science Journal & \\
\hline & Medical Journal of the Islamic Republic of Iran & \\
\hline & Middle East Journal of Scientific Research & \\
\hline & Research Journal of Pharmaceutical, Biological and Chemical Sciences & \\
\hline & Revista Espanola de Enfermedades Digestivas & \\
\hline & Rheumatology International & \\
\hline & Scientific Journal of Kurdistan University of Medical Sciences & \\
\hline & Shiraz E Medical Journal & \\
\hline & Urology & \\
\hline & Urology Journal & \\
\hline & World Neurosurgery & \\
\hline 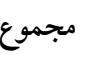 & $(1 \cdots) 190$ & \\
\hline
\end{tabular}

Food and Chemical Toxicology اين جدول به مجله اطلاعات جدول شماره ץ نشان مىدهند در مجموع در

$$
\text { تعلق كرفته است. }
$$
توليدات علمى طب سنتى ايران به FYV مدرك استناد شده همانطور كه نمودار شماره Y نشان مىدهد منابعى كه در

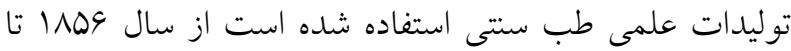

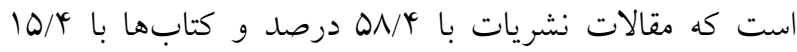

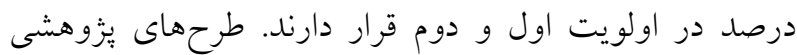
10 ا توليد شده است. بيشترين ميزان استنادات در فاصله سال

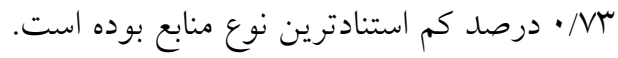

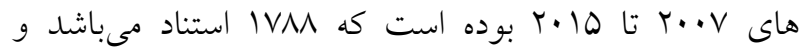

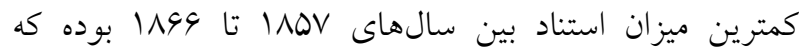
Journal of جدول شماره ه نشان مىدهد كه مجله Ethnopharmacology به عنوان اولين مجله هسته در حوزه

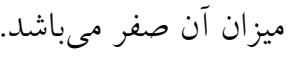
طب سنتى قرار دارد و يّ از آن Journal of Agricultural هند دران and Food Chemistry

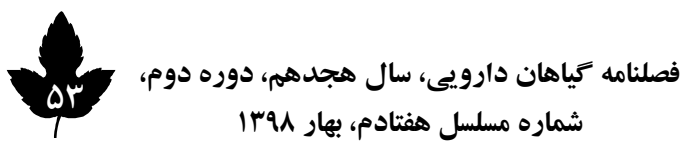




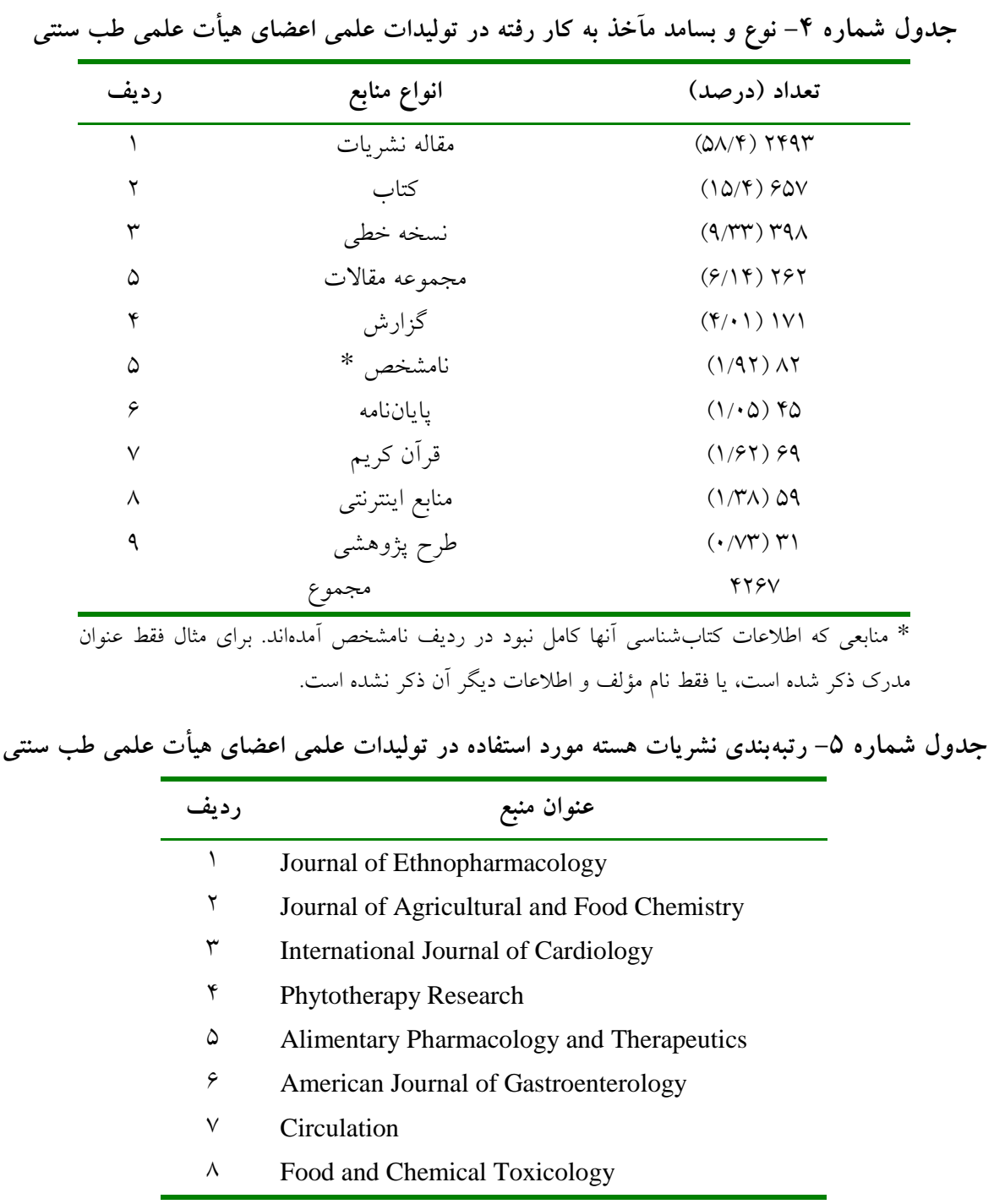

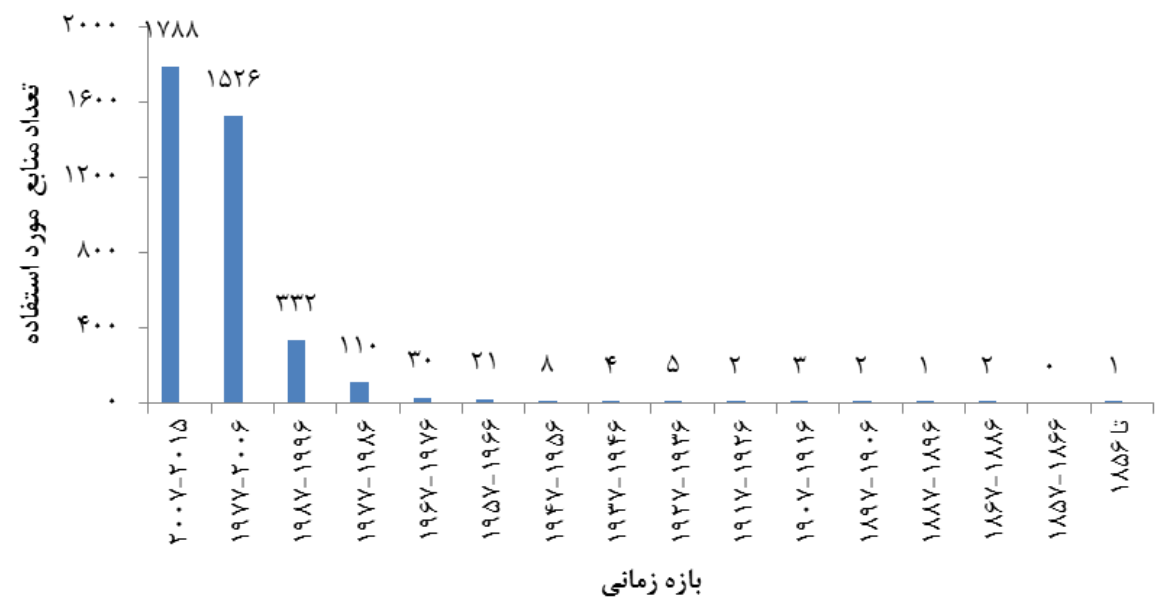

نمودار شماره Y - يوشش زمانى منابع و مآخذ استفاده شده در توليدات علمى اعضاى هيأت علمى طب سنتى كشور 
يافتهاى يزوهش نشان مىدهد كه به 190 توليد علمى نمان

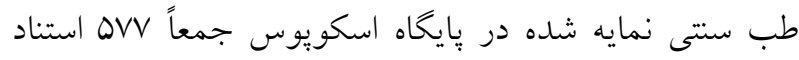

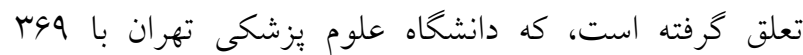

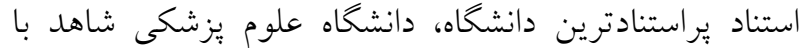

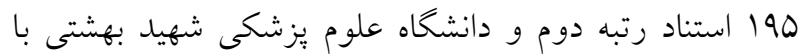

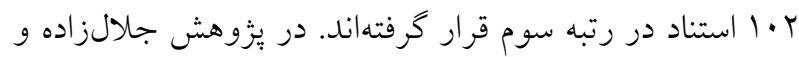

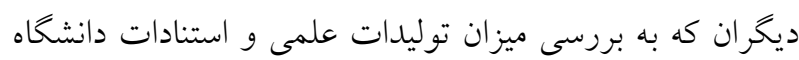

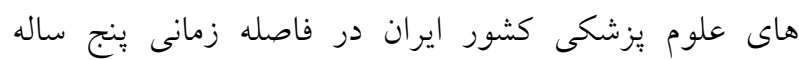

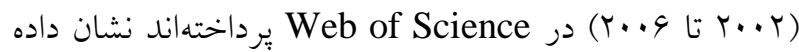
شده است در ميان دانشكاههاى علوم يزشكى تيٍ يك كشور، جهار دانشگاه برتر بر اساس ميزان استنادات به ترتيب دانشگاه

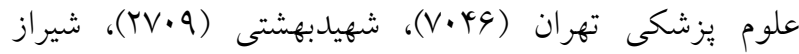

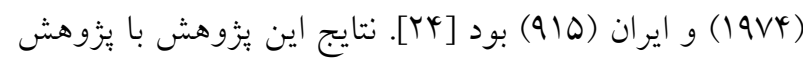
حاضر كه در حوزه طب سنتى است تاحدى متفاوت است،

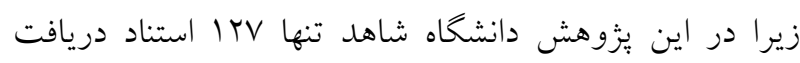

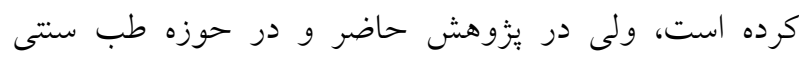

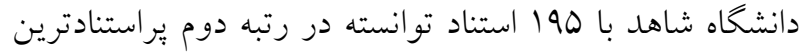

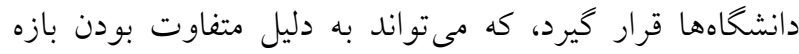

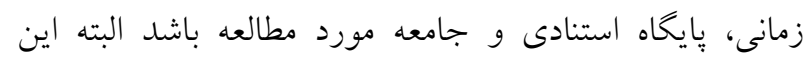

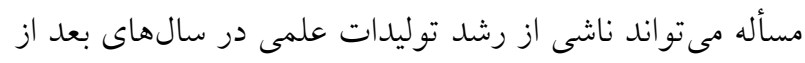

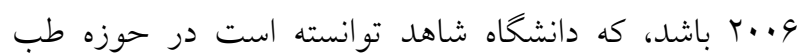
سنتى رشد جشمخيرى داشته باشد. نتايج يزوهش هدهدىنزاد نيز كه تنها يزوهش علمسنجى در

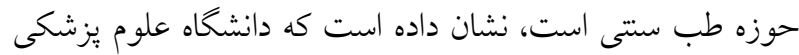

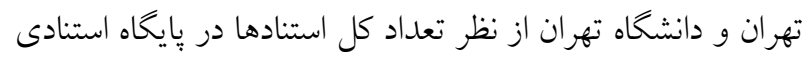
Web of Science

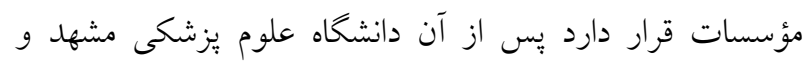

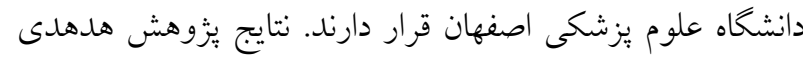
نزاد نيز با يزوهش حاضر متفاوت است و تنها دانشخاه علوم يز شكى تهران در همه يُزوهشها در صدر قرار دارد [10].

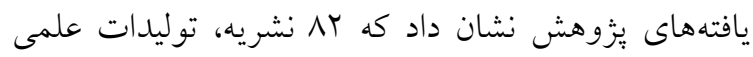

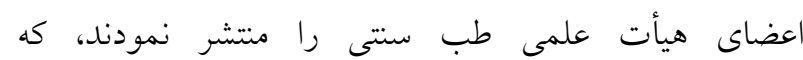
Iranian Red " و "Iranian Journal of Public Health" Crescent Medical Journal

\section{بحث}

توليدات علمى اعضاى هيأت علمى طب سنتى كشور در

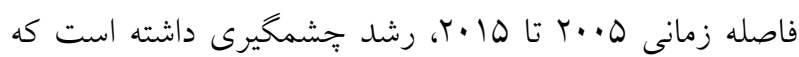

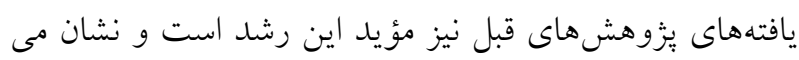

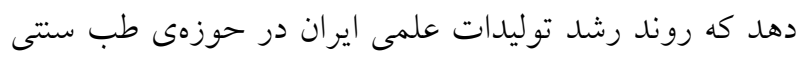

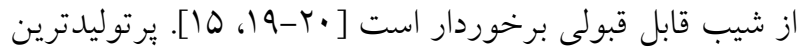

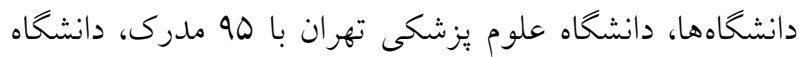

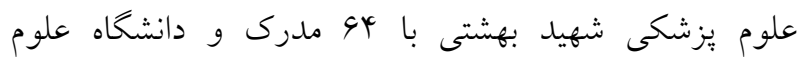

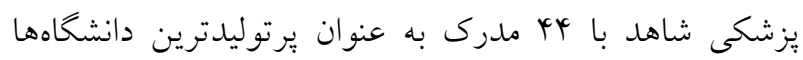

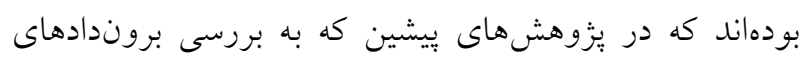

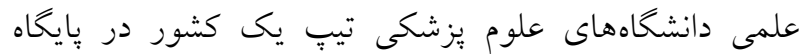

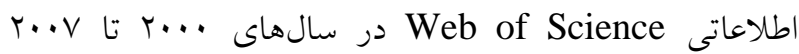
ميلادى برداخته است؛ سهم بروندادهاى علمى دانشخاههاى

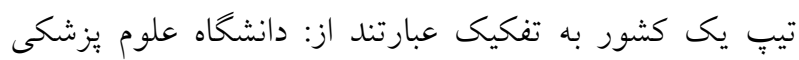

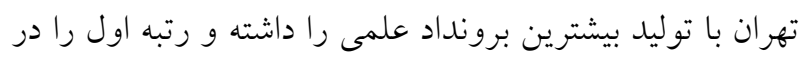

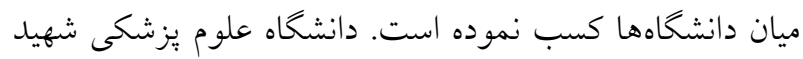

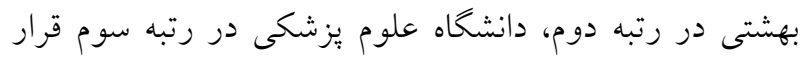

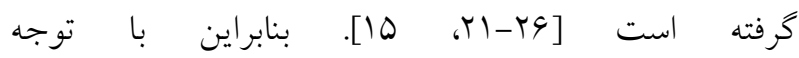

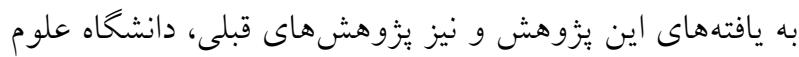

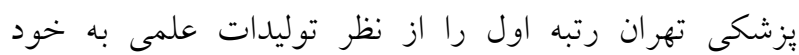

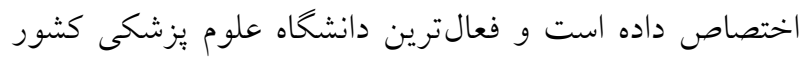

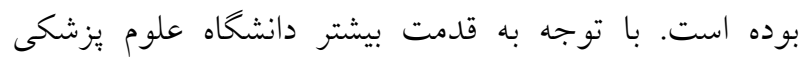

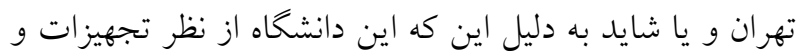
امكانات يزوهشى نسبت به ساير دانشكاهها از وضعيت بهترى برخوردار است كه اين مسأله خود منجر به توليد علمى بيشتر

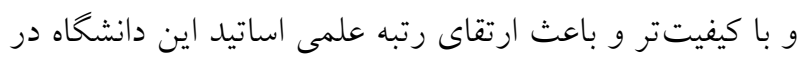

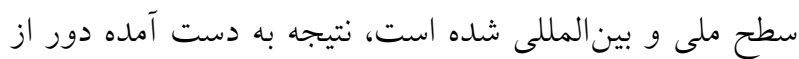

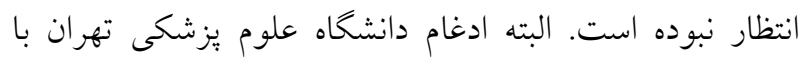
دانشگاه علوم يزشكى ايران در فاصله سالهاى

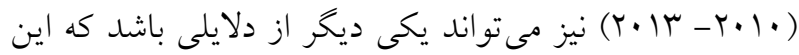

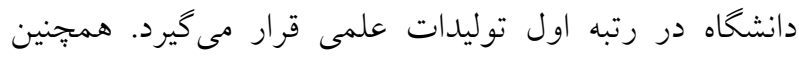

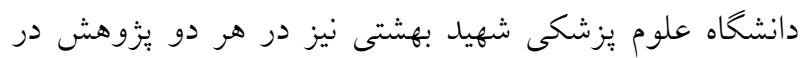
رتبه دوم قرار داشته است.

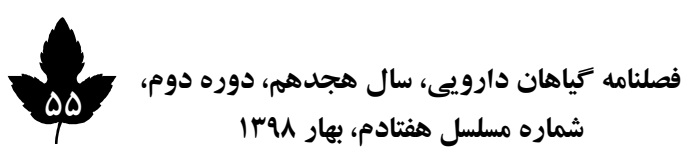


توليد شده است. بيشترين ميزان استنادات در فاصله سالهاى

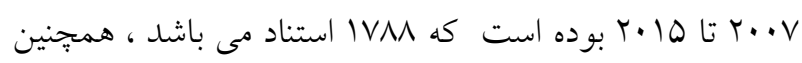

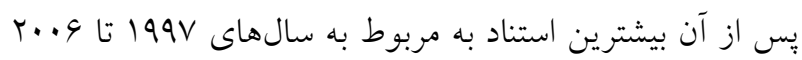

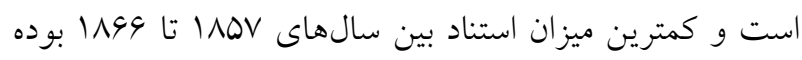

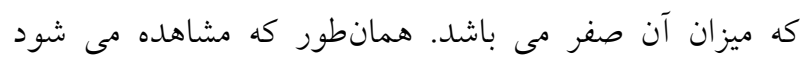

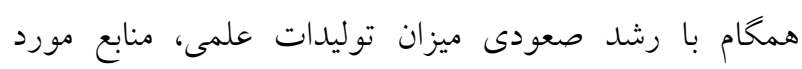

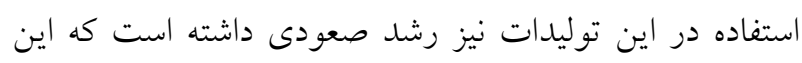

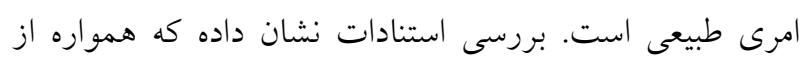

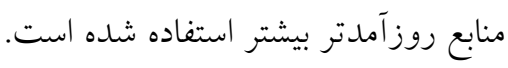
با توجه به اين كه در اين مطالعه بيشتر به مجلات استناد

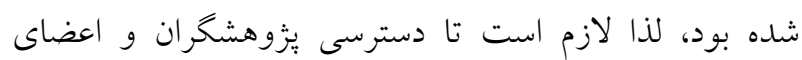

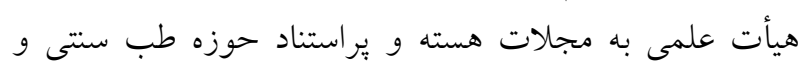

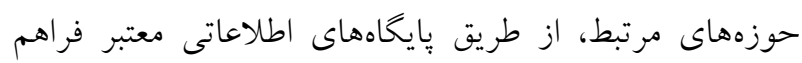

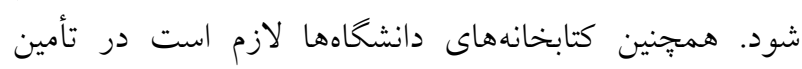

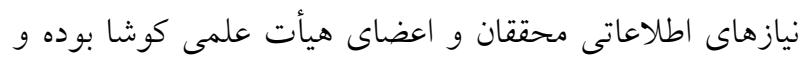

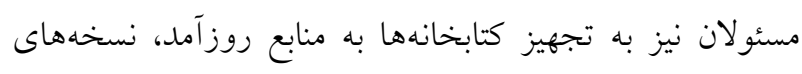
خطى و ساير منابع مورد نياز اهتمام ورزند.

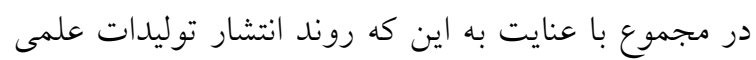

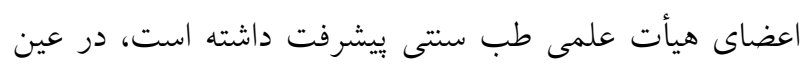

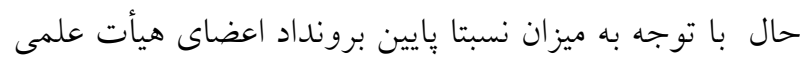

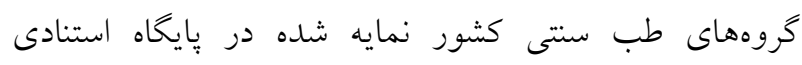

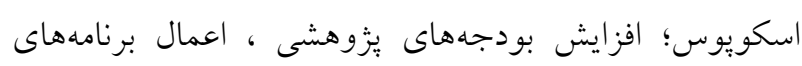

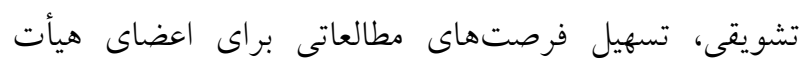

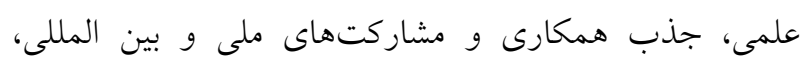

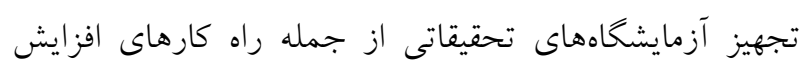

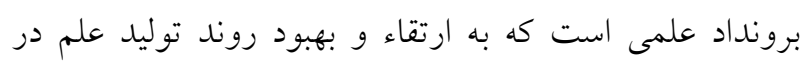

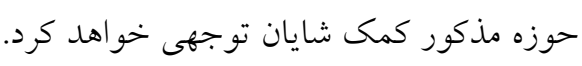

1. Wang JT. Citation Analysis and Theory. InEncyclopedia of Information Science and Technology, Third Edition 2015 (pp: 4507-4515). IGI Global.
مدارى در رتبهى نخست قرار دارند و هر دو نشريه نيز متعلق

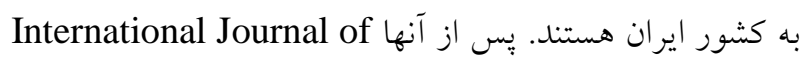
Cardiology Journal of Evidence-Based Complementary and Alternative Medicine

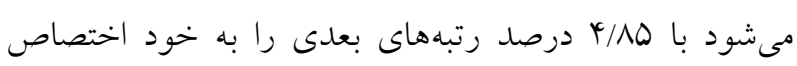

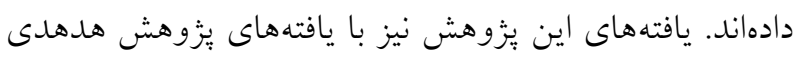

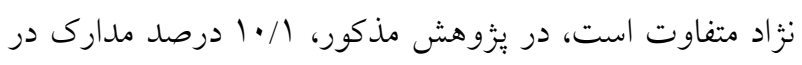

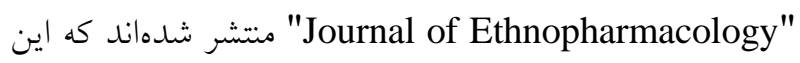
مجله در كشور ايرلند منشر مىشود، اما در يزوهش حاضر اين

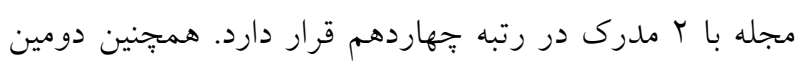

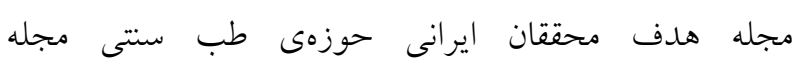

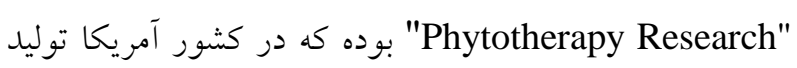

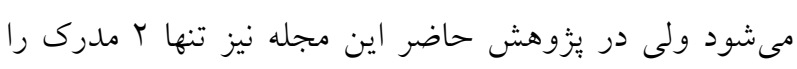

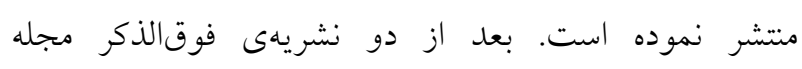
"Iranian Journal of Pharmaceutical Research"

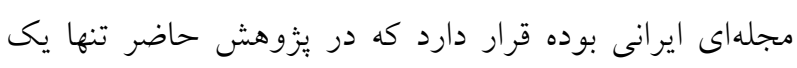

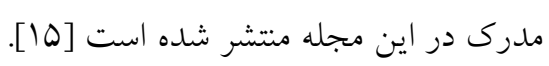
بر اساس يافتهاى يُزوهش هشت مجله به عنوان مجلات

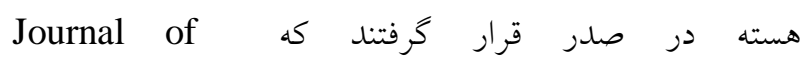
Ethnopharmacology

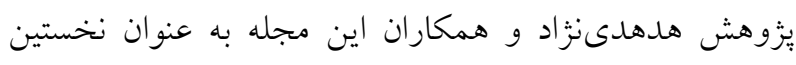

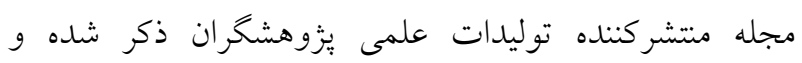

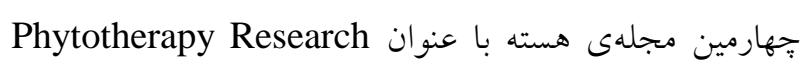

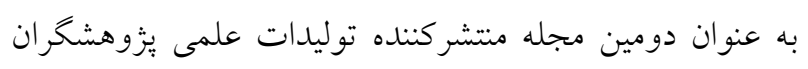
آمده است [10].

يافتهاى يزوهش نشان مى بهند كه منابعى كه در توليدات

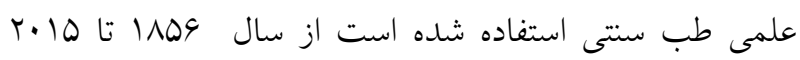

2. Hangartner M. Moving Beyond Citation Analysis. The ANZTLA EJournal 2013 Jun 28 (7): 74-83. 
3. Parthasarathy $G$ and Tomar DC. Trends in Citation Analysis. InIntelligent Computing, Communication and Devices 2015 (pp: 813-821). Springer, New Delhi.

4. Lowe M.S. Reference analysis of the American historical review. collection building [online].available: http://www.emerald insight.com/Insight pdf.jsp? filename=html/output/ published/emerald Full Text Article/pdf/1710220103.pdf. 2003; 22 (1).

5. Egge L.R. R. Introduction to informetrics : quantitative method in library, documentation and information science. Amsterdam: Elsevier science publishers. 1990: 203.

6. Ferrante B.K.K. Bibliometrics: Access in library literature collection management. 1978, 2: p. 199-204.

7. Sarli CC, Dubinsky EK and Holmes KL. Beyond citation analysis: a model for assessment of research impact. JMLA. 2010 Jan; 98 (1): 17.

8. Dymond S, May RJ, Munnelly A and Hoon AE. Evaluating the evidence base for relational frame theory: A citation analysis. The Behavior Analyst 2010 Apr 1; 33 (1): 97-117.

9. Vallmitjana $\mathrm{N}$ and Sabaté LG. Citation analysis of $\mathrm{Ph}$. D. dissertation references as a tool for collection management in an academic chemistry library. College \& Research Libraries 2008 Jan 1; 69 (1): 72-82.

10. Clarke R. A Citation analysis of Australian Information Systems Researchers: Towards a new ear?. Australian Journal of Information Systems 2008; 15 (2): 35-56.

11. Garfield E. Citation indexing. Its theory and application in science technology and humanities. New York: John Wiley and Sons, 1979 :178.

12. Maharana B, Nayak K and Sahu NK. Scholarly use of web resources in LIS research: a citation analysis. Library Rev. 2006 Dec 1; 55 (9): 598607.

13. Van Eck NJ and Waltman L. Appropriate similarity measures for author co-citation analysis. Journal of the Association for Information Science and Technol. 2008 Aug 1; 59 (10): 1653-61.

14. Liu Z. Visualizing the intellectual structure in urban studies: A journal co-citation analysis (19922002). Scientometrics 2005 Feb 22; 62 (3): 385402.

15. Hodhodinezhad N, Zahedi Anaraki R and Ashrafi Rizi H. The Scientific Production and Scientific Mapping of Iranian Researchers in Traditional Medicine during 1990-2011 in Web of Science. Health Information Management Vol 9, No 4; 2012 (serial No 26) [Internet]. 2012 Oct 6; Available from: http://him.mui.ac.ir/index.php/him/article/view/815 16. Traditional Iranian Medicine and the need for its revival and development. teb. 2010; 19 (3) :63-0 URL: http://tebvatazkiyeh.ir/article-1-42-fa.html

17. WHO, Traditional medicine [online]. Available from:

URL:

http://WWW.Who.int/topics/traditional medicine/en, 2017.

18. Naseri $M$, Rezayeezadeh $H$, Choopani $R$ and Anooshiravani M. A Review on generalities of Iranian traditional medicine. Tehran: share Teran, 2011, p. 80-81. [Persian]

19. Abdekhoda H, Ghazi MirSaeed S, Nourzi A. Evaluation of Scientific Production of Iranian Medical domain based on the document indexed from scientific journals in chosen databases, between 2005-2009. payavard 2010; 4 (2 and 1): 18-30. [Persian]

20. Riahi A and Sohbatiha F. Visualization of scientific products and journals at the global level: Casting a glance at Islamic Republic of Iran. Journal of Modern Medical Information Sciences 2015; 1 (2): 1-11 URL: http://jmis.hums.ac.ir/article-1-52-fa.html. [Persian]

21. Eskrootchi R, Hassanzadeh $H$, Gohari $M$ and Jamshidi R. Trend of Iranians' Scientific Papers in Medical Fields in 1978-2007. JHA. 2009; 12 (37):29-38. [Persian]

22. Ranjbar-pirmousa $Z$ and Zarei H. Situation of

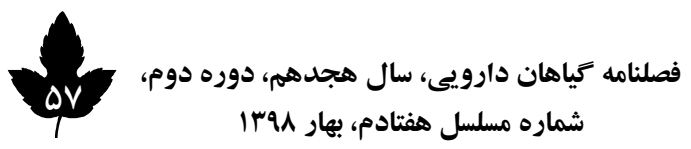


Articles Published and their Citations of Tehran and Shahid Beheshti Universities of Medical Sciences in Web of Science Database. RME. 2016; 8 (3): 24-33 URL: http://rme.gums.ac.ir/article-1365-fa.html [Persian]

23. Amirsalari S, Khalili Matinzadeh Z, Afshar Peiman Sh, Javadipour $M$ and Azizabadi Frahani M. [Tehran University of Medical Sciences: Participation in Twenty Five Percent of Pediatric Science Production in Iran]. Iranian Journal of Pediatrics 2008; 18 (1): 21-27.[Persian]

24. Jalalzadeh Asrejadidi S, Biglu M H and Rafi A. The Study of "Matthew Effect" on Science Productions of Iranian Medical Universities on the basis of "Power- law Relationship" in a Five Year Period in the Web of Science. JIPM. 2011; 26 (4):
1106-1120 URL: http://jipm.irandoc.ac.ir/article-11537-fa.html [Persian]

25. Abbasi $\mathrm{F}$ and Beigloo $\mathrm{MH}$. The relationship between qualitative and quantitative indicators in the scientific productivity of medical universities of Iran in the database. JHIM. 2011; 8 (6): 851842. [Persian]

26. Hassanzaeh Esfanjani HM, Valinejad A, Taghipour M, Parisa F, Bakhtiarzadeh A and Bourghi H. A scientometric overview of 30 years (1978-2007) of medical sciences productivity in Iran. Medical Science Journal of Islamic Azad Univesity 2010; 20 (3): 212-220. [Persian] 


\title{
Study the Scientific Productions of the Faculty Members of Traditional Medicine at Universities of Medical Science in Iran Medical in the Scopus Citation Database (2005-2015)
}

\author{
Kazerani M (Ph.D.) ${ }^{1^{*}}$, Bagheri Ghahfarrokhi M (M.Sc.) ${ }^{1}$, Shekofteh M (Ph.D.) ${ }^{1}$ \\ 1-Department of Medical Library and Information Science, Faculty of Paramedical \\ Sciences, Shahid Beheshti University of Medical Sciences, Tehran, Iran \\ *Corresponding author: Faculty of Paramedical Sciences, Shahid Beheshti University of \\ Medical Sciences, Qods Sq, Darband st., Tehran, Iran \\ Tel: +98-21-22718528, Fax: +98-21-22721150 \\ E-mail: kazerani.m@gmail.com
}

\begin{abstract}
Background: One of the most important aspects of research is the evaluation of scientific production, and this is important in traditional medicine due to its specific application in the treatment of diseases today.

Objective: The purpose of this study was to analyze the scientific products of faculty members of Traditional Medicine in Iranian Medical Sciences Universities indexed in Scopus Citation Database between 2005 and 2015.

Methods: This study is a descriptive survey with scientometric approach. Required data were extracted from Scopus Citation Database by September 21, 2015 and descriptive statistics were used to analyze the data.

Results: Scientific production of the faculty members of the traditional medicine had a sustained upward trend, Tehran University has been known as the best in production ( 95 certificates) and the best in citation (369 citations).Iranian Journal of Public Health and Iranian Red Crescent Medical Journal have both published the largest scientific publications of the faculty members of traditional medicine in the country (each 16 certificates). Articles of journals $(58.4 \%)$ and books $(15.4 \%)$ were the most used sources by traditional faculty members. 8 magazines were selected as the core journals in the field of traditional medicine; the Journal of Ethnopharmacology was the first journal in this field. The maximum rate of citations is related to the references since 2007 to 2015.

Conclusion: Access of researchers to core journals in the field of traditional medicine through valid databases, increase the research budgets, apply incentive programs, facilitation for sabbatical leaves, and the provision of research laboratories are some ways to Improve the quality and quantity of scientific production in this field.
\end{abstract}

Keywords: Citation analysis, Faculty members, Traditional medicine, Scopus, University of Medical Sciences, Iran 